\title{
Avaliação das Vazões Alocáveis na Bacia Hidrográfica do Rio dos Bois e sub-bacia do Rio do Peixe, Estado de Goiás
}

\author{
Santos, Harlen Inácio, Oliveira, Leandro Gonçalves, Fioreze, Ana Paula \\ Universidade Federal do Goiás - \\ harlen@semarh.goias.gov.br, leandro@semarh.goias.gov.br, anafioreza@semarh.goias.gov.br
}

Recebido: 03/05/05 - revisado: 07/06/05 - aceito: 27/10/05

\section{RESUMO}

O presente trabalho avalia as vazões passíveis de alocação através da outorga de direito de usos na Bacia Hidrográfica do Rio dos Bois e sub-bacia do Rio do Peixe, no Estado de Goiás, para subsidiar os instrumentos de gestão dos recursos hídricos, previstos na Lei Federal 9.433/97, com ênfase à cobrança pelo uso dos recursos hídricos.

A Bacia Hidrográfica do Rio dos Bois tem área de drenagem de 34.552,04 km², correspondente a cerca de $10 \%$ da área total do Estado de Goiás e conta com boa disponibilidade de dados fluviométricos, fornecidos por vinte estações, com séries históricas e distribuição que permitiram a regionalização das vazões de saída dessa bacia.

Através do programa computacional RH 3.0, desenvolvido pela Fundação Rural Mineira - RURALMINAS e Universidade Federal de Viçosa, com o apoio da Secretaria de Recursos Hidricos do Ministério do Meio Ambiente, foi calculada a vazão com $95 \%$ de permanência $\left(Q_{95}\right)$ para a saída da bacia do Rio dos Bois, obtendo-se o valor de $118.100 \mathrm{l} / \mathrm{s}$.

$O$ Conselho Estadual de Recursos Hidricos de Goiás estabeleceu, através da resolução 09/2005, a $Q_{95}$ como vazão de referência para a outorga de direito de uso das águas de domínio estadual e como vazão máxima outorgável, a porção de $70 \%$ da $Q_{95}$, ou, para a Bacia Hidrográfica do Rio dos Bois, $82.670 \mathrm{l} / \mathrm{s}$.

Para verificação da viabilidade de emprego desta vazão de referência e da porção alocável, procedeu-se levantamento dos critérios de outorga adotados em onze Estados brasileiros.

Na sub-bacia do Rio do Peixe, com área de drenagem de 287,49 $\mathrm{km}^{2}$, a inexistência total de dados hidrológicos e a impossibilidade de transposição de dados pela reduzida área de drenagem impedem o cálculo da $Q_{95}$ e sua utilização como vazão de referência. Tal situação se repete na grande maioria das bacias hidrográficas de pequeno porte no Estado de Goiás.

Nestes casos, a resolução 09/2005 do CERH-GO determina que seja utilizada como vazão de referência a menor vazão medida no manancial, preferencialmente em período de estiagem e com método de precisão.

Para obtenção da vazão de referência na sub-bacia hidrográfica do Rio do Peixe foram realizadas medições de vazão através do molinete hidrométrico, em quatro pontos da bacia, ao longo do manancial principal, por quatro oportunidades, de junho de 2003 a abril de 2004.

A partir destas medições, obteve-se como vazão de referência na saída da sub-bacia do Rio do Peixe, o valor de $627 \mathrm{l} / \mathrm{s}$, o que corresponde à menor vazão medida no local e forneceu como resultado com base nos critérios adotados pela autoridade outorgante a porção alocável de $94 \mathrm{l} / \mathrm{s}$.

Palavras-chave: vazões alocáveis; outorga; bacia hidrográfica.

\section{INTRODUÇÃO}

O aprimoramento dos instrumentos de gerenciamento da água no Brasil está relacionado com a recente percepção de finitude deste recurso, hoje considerado estratégico e ameaçado (Tundisi et al, 2002).

Considerar a água como um recurso econômico é, de acordo com Dinar e Subramanian (1997), a chave para alcançar a alocação mais efici- ente da água disponível, além de incentivar sua conservação.

Os instrumentos de gestão dos recursos hídricos, definidos na Lei Federal 9.433, de 07 de janeiro de 1997 são seis: os Planos de Recursos Hídricos, o enquadramento dos corpos de água em classes, a outorga dos direitos de uso de recursos hídricos, a cobrança pelo uso de recursos hídricos, a compensação aos municípios e o Sistema de Informações sobre Recursos Hídricos. 
A implementação desses instrumentos, por dispendiosa e de resultados lentos, só se justifica nas bacias hidrográficas com usos atuais ou potenciais significativos em função da disponibilidade hídrica existente. Nestas situações a água pode funcionar como fator limitante das atividades sócioeconômicas e traduzir-se em recurso gerador de conflitos e prejuízos.

Constanza (1997) introduz o conceito da sustentabilidade a partir da sua dimensão ecológica, ou seja, a discussão do crescimento econômico deve obrigatoriamente passar pela capacidade de suporte dos ecossistemas.

A questão central em recursos naturais e economia ambiental é manter alocações eficientes. A idéia central das economias modernas é permitir as condições necessárias para que os mercados tenham eficiência nessa alocação (Perman et al, 1999).

Boulding (1993) defende uma nova orientação como condição para alcançarmos uma economia firmemente sustentável. Ele argumenta que na economia a mensuração do sucesso econômico é feita pelos fluxos de matérias processadas ou transformadas e, de uma forma ou de outra, os resíduos desses processos estarão sempre conosco. Esse estado "sustentável" da economia pressupõe algumas condições, entre elas: a manutenção da utilidade de consumo; o gerenciamento dos recursos naturais para a produção futura e a atenção às condições mínimas de estabilidade e recuperação dos ecossistemas.

Este diálogo economia versus ambiente não é tão recente como se imagina. Ainda em 1904, na Alemanha, durante a organização da primeira Gernossenschaft (autoridade do rio) no Vale do Rhur este processo foi iniciado. À época, devido à concentração de indústrias pesadas, os rios daquela bacia apresentavam um potencial de poluição entre os mais elevados da Europa.

Os economistas têm acentuado, em seu diálogo com ambientalistas, o papel de instrumentos econômicos que utilizam a valoração dos bens naturais e estabelecem a precificação destes.

Nesse contexto recomenda-se a exclusão das visões meramente utilitaristas antropocêntricas. Existe direito à existência para além dos seres humanos, plantas e animais, por exemplo. Preço e valor não são, neste enfoque, palavras sinônimas. Mota (2001) simplifica esse dilema assim: como é necessário que se estabeleça a verdade na questão do valor do meio ambiente, mas não se pode estimar o valor dos ativos naturais, calcula-se uma importância que possa simbolizar um sinal de preço. Ele defende ainda que o conceito mais usado na valoração de ativos naturais é o da disposição de pagar e refere-se à máxima propensão a pagar que uma pessoa revela ao usar um recurso ambiental, considerando na análise seu limite orçamentário, sua preferência, seu altruísmo, sua renda e outros fatores atitudinais.

A cobrança na Bacia Hidrográfica do Rio Paraíba do Sul é o mais importante exemplo da implementação desse instrumento no Brasil. Primeiro, por estar sendo realizada efetivamente desde 2003, transformando-se quase em um laboratório de observação para todo o país e, também, pelo fato de que mesmo sendo um rio de domínio federal, o processo está sendo conduzido pelo Governo Federal em conjunto com os Estados de São Paulo, Minas Gerais e Rio de Janeiro. É o primeiro teste da aplicação plena da Lei Federal 9.433/1997.

No presente trabalho, realizado na Bacia Hidrográfica do Rio dos Bois, no Estado de Goiás, estudou-se sua disponibilidade hídrica e de sua subbacia do Rio do Peixe, onde procedeu-se ainda a avaliação das vazões passíveis de outorga para diferentes usos e posterior aplicação da cobrança decorrente destes usos. O objetivo é discutir a sustentabilidade dos usos atuais dos recursos hídricos em comparação com as vazões passíveis de alocação.

Estudos dessa natureza produzem resultados que, devidamente considerados, são ferramentas essenciais para a tomada de decisão na alocação das vazões hídricas e, por conseqüência, para a elaboração de Planos de Recursos Hídricos e para o estabelecimento da cobrança pelo uso da água.

\section{A BACIA HIDROGRÁFICA DO RIO DOS BOIS}

A Bacia Hidrográfica do Rio dos Bois (Figura 1), onde se localiza a área de estudo, inclui território de 46 municípios, dos quais 33 municípios têm suas áreas urbanas inseridas na bacia. A região abriga cerca de 401.316 habitantes, o que significa 7,42\% da população total do Estado de Goiás.

Essa bacia tem uma área de drenagem de $34.552,04 \mathrm{~km} 2$, o que corresponde a aproximadamente $10 \%$ da área total do Estado de Goiás. Situase no centro-sul desse Estado e está contida entre os meridianos $49^{\circ} 07^{\prime}$ e $52^{\circ} 26^{\prime}$ de longitude a oeste de Greenwich e os paralelos $16^{\circ}$ e $18^{\circ} 36^{\prime}$ de latitude ao sul do Equador.

O Rio dos Bois, que dá nome à bacia, nasce na Serra do Congumé, na Fazenda Quilombo, na cota 920 metros, dentro do município de Americano 


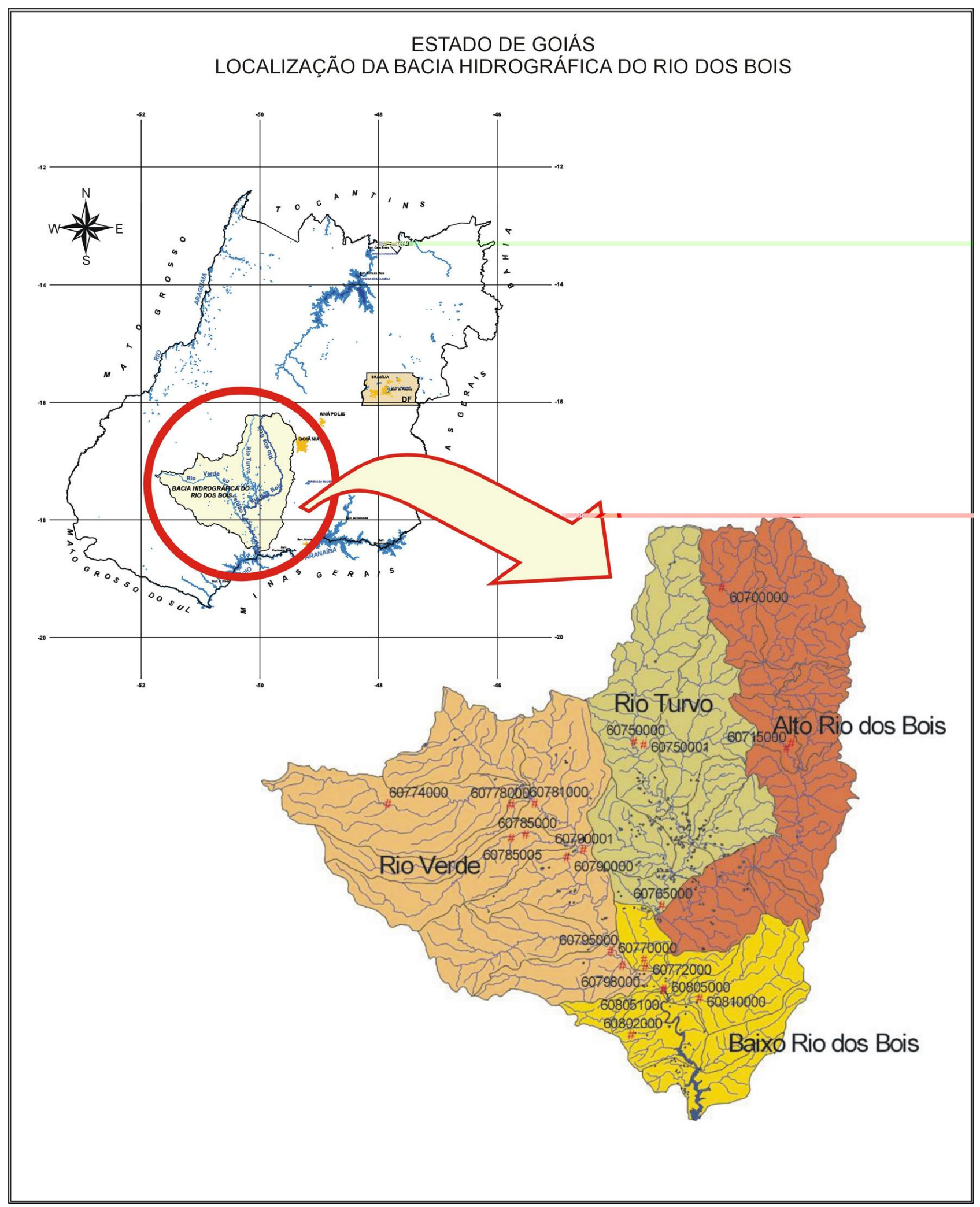

Figura 1 - Localização das estações fluviométricas existentes na Bacia Hidrográfica do Rio dos Bois, Estado de Goiás 
do Brasil, e percorre uma extensão de $528 \mathrm{~km}$, até desaguar na margem direita do rio Paranaíba, na cota de aproximadamente 380 metros, a jusante do município de Gouvelândia.

O Comitê da Bacia Hidrográfica do Rio dos Bois foi criado pelo Decreto Estadual no 5.826, de 11 de Setembro de 2003, e encontra-se com sua Diretoria provisória designada em busca da definição de sua composição final e seu Regimento. Estas providências devem propiciar a definição dos instrumentos de gestão dos recursos hídricos, dentre eles a cobrança pelo uso da água na região.

Conforme dados do sistema de outorga de direito de usos da água de domínio do Estado de Goiás, em novembro de 2004, os usos regulares nesta bacia hidrográfica totalizavam 580, dos quais 345 como usos consuntivos e 235 não consuntivos (Tabelas 1 e 2).

A sub-bacia hidrográfica do Rio do Peixe (Figura 1) pode ser classificada como de terceira ordem no domínio do Estado de Goiás, pois está inserida na Bacia Hidrográfica do Rio Anicuns (segunda ordem), que se localiza na Bacia Hidrográfica do Rio dos Bois (primeira ordem), tributário do Rio Paranaíba, de domínio federal.

A área total da sub-bacia do Rio do Peixe é de $287,48 \mathrm{Km}^{2}$, englobando porções territoriais de 4 municípios (Caturaí, Inhumas, Goianira e Trindade). O único município com área urbana na subbacia é Caturaí.

A sub-bacia estudada (Bacia do Rio do Peixe) apresenta diferentes usos, sobretudo agricultura irrigada e abastecimento doméstico. O município de Caturaí não dispõe de sistema de esgotamento sanitário.

A área da Bacia Hidrográfica do Rio dos Bois possui uma boa intensidade de precipitação, com uma média de $1500 \mathrm{~mm}$ ao ano, e apresenta um padrão de distribuição característico da região do Cerrado. O período chuvoso ocorre de outubro a abril, cuja concentração da pluviometria determinase entre os meses de dezembro e março, sendo responsável por $80 \%$ do total de chuvas.

O uso das águas para abastecimento público é feito, principalmente, pelas águas de superfície e, secundariamente, por águas subterrâneas através de concessões feitas à Companhia de Saneamento de Goiás S/A (SANEAGO), e em alguns municípios pela própria Prefeitura. Cerca de $70 \%$ dos domicílios da Bacia são abastecidos pela rede pública de abastecimento, $29 \%$ são abastecidos por poços e $1 \%$ por outros meios.

Em relação aos efluentes sanitários, apenas 6 municípios dos 33 que têm área urbana na Bacia
Hidrográfica do Rio dos Bois, possuem sistemas de coleta e tratamento de esgotos domésticos. São eles: Anicuns, Guapó, Palmeiras de Goiás, Paraúna, Rio Verde e Santa Helena de Goiás.

Existem inúmeros conflitos em diversos mananciais hídricos da Bacia Hidrográfica, como o Rio dos Bois, Rio Turvo, Verde, Verdão, Ribeirão Santa Bárbara, Ribeirão Bonsucesso, entre outros. Os principais conflitos ocorrem entre os usuários do setor de abastecimento público e os da agricultura irrigada.

Os conflitos pela água totalizaram 78 ocorrências entre 1998 e 2004, considerando apenas aqueles denunciados e arbitrados pelo órgão gestor dos recursos hídricos.

Estes conflitos envolvem principalmente captações para irrigação de culturas e barramentos de cursos d'água. A disputa mais importante e que perdura ocorre entre três diferentes setores usuários: o industrial, através de uma indústria sucroalcoleira; o abastecimento urbano, pelo sistema de tratamento de água do município de Bom Jesus de Goiás; e o de agricultura irrigada, através de quatro equipamentos de pivot central instalados.

\section{METODOLOGIA}

É possível utilizar, como vazão de referência, valores obtidos no campo, através de medições diretas, ou valores calculados a partir de séries históricas de vazão e pluviosidade.

As vazões obtidas a partir de dados de estações pluviométricas e fluviométricas representam com maior segurança o comportamento de longo termo das vazões da bacia.

Na Bacia Hidrográfica do Rio dos Bois, os dados são fornecidos por vinte estações, distribuídas nas suas principais sub-bacias (Figura 1), sendo que a maioria das séries históricas tem aproximadamente 30 anos (Gama, 2004).

Para testar a confiabilidade dos dados hidrológicos disponíveis foi calculada a correlação entre as vazões médias mensais de longo período calculadas para a estação mais próxima da saída (Estação Ponte Sul Goiana) e a estação situada à montante (Estação Maurilândia). Os dados testados correspondem a um período de 29 anos, de 1967 a 1995 (Gráfico 1).

Segundo Tucci (1997), a transferência de dados hidrológicos pode ser realizada com boa aproximação quando a diferença entre a área de drenagem até a estação e a área de drenagem total 
Tabela 1 - Usos consuntivos de águas na Bacia do Rio dos Bois, Estado de Goiás, até novembro/2004.

\begin{tabular}{|l|l|c|c|c|c|}
\hline Tipo de uso & Tipo de captação & Outorgas requeridas & Outorgas expedidas Vazão requerida & Vazão outorgada \\
\hline Irrigação & Direta & 287 & 167 & $26.422,31 \mathrm{l} / \mathrm{s}$ & $14.294,28 \mathrm{l} / \mathrm{s}$ \\
\hline Irrigação & Barramento & 234 & 166 & $19.813,90 \mathrm{l} / \mathrm{s}$ & $13.430,561 / \mathrm{s}$ \\
\hline Indústria & Direta & 13 & 10 & $2.324,331 / \mathrm{s}$ & $2.174,131 / \mathrm{s}$ \\
\hline Indústria & Barramento & 2 & 2 & $228,851 / \mathrm{s}$ & $228,85 \mathrm{l} / \mathrm{s}$ \\
\hline TOTAL & & $\mathbf{5 3 6}$ & $\mathbf{3 4 5}$ & $\mathbf{4 8 . 7 8 9 , 3 9 ~ 1 / s}$ & $\mathbf{3 0 . 1 2 7 , 8 2 ~ 1 / s}$ \\
\hline
\end{tabular}

Tabela 2 - Usos não consuntivos de águas na Bacia do Rio dos Bois, Estado de Goiás, até novembro/2004.

\begin{tabular}{|l|l|c|c|c|c|}
\hline Tipo de uso & Tipo de captação & Outorgas requeridas & Outorgas expedidas & Vazão requerida & Vazão outorgada \\
\hline Piscicultura & $\begin{array}{l}\text { Direta/ } \\
\text { barramento }\end{array}$ & 18 & 13 & $705,51 \mathrm{l} / \mathrm{s}$ & $471,43 \mathbf{1 / s}$ \\
\hline $\begin{array}{l}\text { Abastecimento } \\
\text { Público }\end{array}$ & Direta & 18 & 9 & $1.233,001 / \mathrm{s}$ & $647,001 / \mathrm{s}$ \\
\hline Barramento & Não há & 246 & 213 & 0 & 0 \\
\hline TOTAL & & $\mathbf{2 8 2}$ & $\mathbf{2 3 5}$ & $\mathbf{1 . 9 3 8 , 5 1 ~ 1 / s}$ & $\mathbf{1 . 1 1 8 , 4 3 ~ 1 / s}$ \\
\hline
\end{tabular}

Gráfico 1 - Correlação entre as vazões médias mensais da Estação Maurilândia e Estação Ponte Sul Goiana, Bacia Hidrográfica do Rio dos Bois, Estados de Goiás.

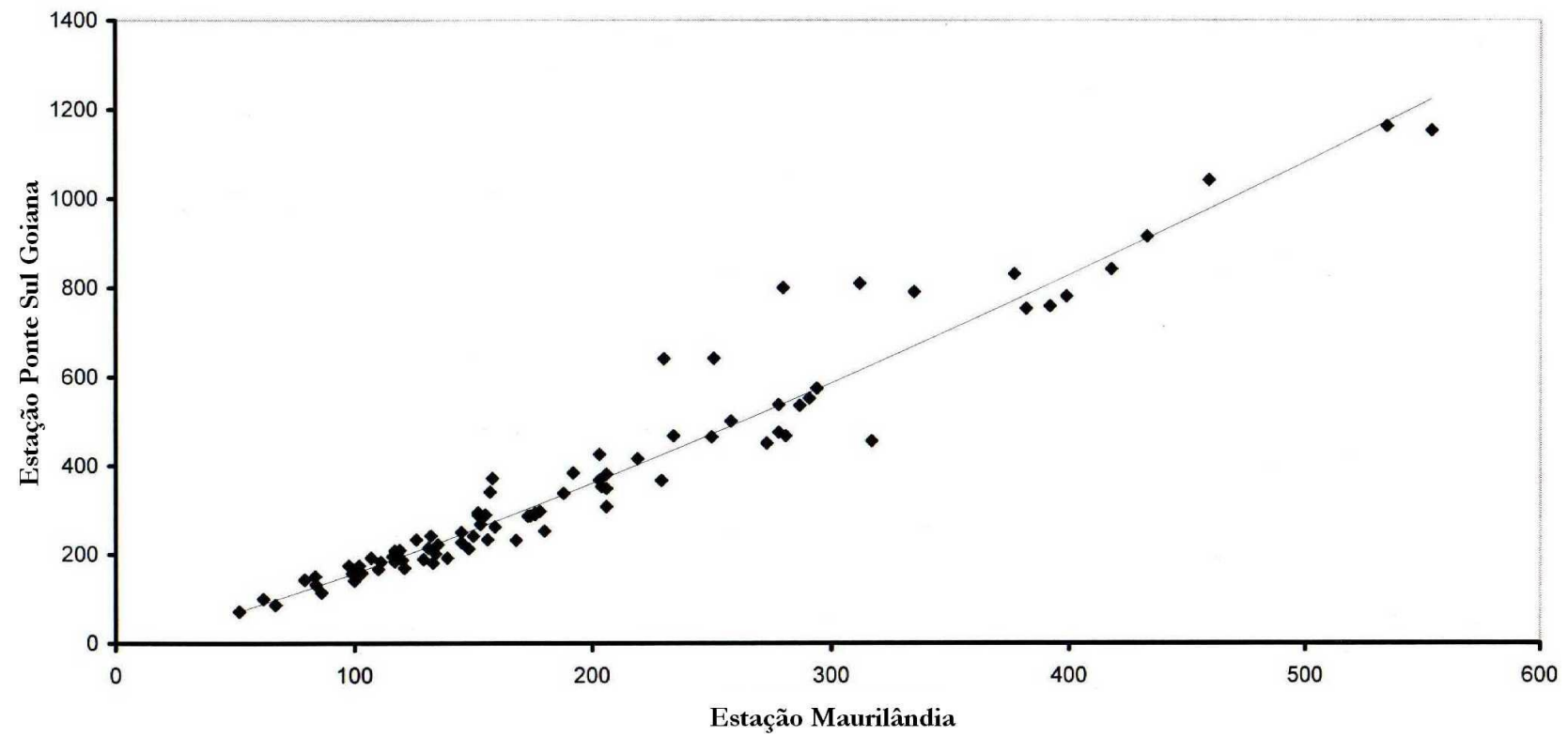

da bacia não supera os $15 \%$. Na bacia do Rio dos Bois, a diferença entre a área total e a área de drenagem até a Estação Ponte Sul Goiana é de 12\%, conforme demonstra a Tabela 3 .

Cortês (2004) realizou a validação de modelos de regionalização de vazão na Bacia do Rio dos
Bois, onde constatou que as equações regionalizadas contendo todas as variáveis independentes apresentaram coeficientes de determinação, $\mathrm{R}^{2}$, acima de 0,95 e erros relativos médios entre os valores observados e estimados relativamente baixos, validando assim o uso dessas equações. 
Tabela 3 - Área de drenagem da bacia do Rio dos Bois e da última estação fluviométrica, e diferença entre elas.

\begin{tabular}{|l|c|c|}
\hline Abrangência & Área de drenagem $\left.\mathbf{( K m}^{\mathbf{2}}\right)$ & Diferença entre as áreas \\
\cline { 1 - 2 } Bacia do Rio dos Bois & 34.718 & \multirow{2}{*}{$12,04 \%$} \\
\cline { 1 - 2 } Primeira estação à montante da saída & 30.536 & \\
\hline
\end{tabular}

Fonte: GAMA, 2004

As vazões de permanência para a Bacia Hidrográfica do Rio dos Bois foram calculadas empregando-se o programa RH 3.0, que é um programa computacional para regionalização hidrológica que possibilita obter variáveis hidrológicas, como vazões máximas, mínimas e média de longo período, curvas de permanência e de regularização.

A versão do programa empregada na elaboração do Plano Diretor de Irrigação em Goiás (Gama, 2004) foi desenvolvida com o apoio da Secretaria de Recursos Hídricos do Ministério do Meio Ambiente, e vem sendo amplamente utilizada em estudos de regionalização hidrológica em âmbito nacional e internacional (www.ufv.br/ dea/ hidrotec).

O programa executa a regionalização das vazões máximas diárias anuais para períodos de retorno de $2,5,10,20,50,100$ e 500 anos, mínimas de duração de 1, 7, 15, 30, 60, 90, 120, 150 e 180 dias, com períodos de retorno de 2, 5, 10 e 20 anos, médias de longo período, curvas de permanência de vazões e curvas de regularização.

A $Q_{90}$ é a vazão garantida em $90 \%$ do tempo, ou seja, em $10 \%$ do tempo, ou cerca de 36 dias por ano, esta vazão não é atendida. Sua adoção implicaria na redução das vazões captadas, através de racionamento, ou na suspensão de alguns ou todos os usos por um período de tempo importante.

A $Q_{95}$ confere um grau de segurança maior à decisão do gestor de recursos hídricos, uma vez que representa a vazão com garantia de ocorrência em $95 \%$ do tempo, ou seja, o risco de desabastecimento de parte dos usos ou de necessidade de racionamento fica restrito a $5 \%$ do tempo, ou cerca de 18 dias por ano.

A adoção da $Q_{99}$ praticamente eliminaria o risco de suspensão dos usos outorgados na bacia, pois estes usos não seriam atendidos apenas em $1 \%$ do tempo, ou pouco mais de 3 dias. No entanto, esta vazão não é representativa da disponibilidade hídrica na bacia hidrográfica durante a maior parte do tempo e restringiria os usos a uma pequena fração daquela disponibilidade.

Na sub-bacia do Rio do Peixe foram realizadas quatro campanhas de medições de vazão pontu- ais em quatro oportunidades distintas, duas no período de estiagem e duas no período chuvoso, ao longo de um ano, abrangendo diferentes pontos demarcados previamente.

Estas medições foram realizadas pelos autores deste trabalho, com apoio de técnicos e equipamentos da Superintendência de Recursos Hídricos da Secretaria Estadual do Meio Ambiente e dos Recursos Hídricos.

Os pontos demarcados para estas medições foram:

- $\quad$ P1 - localizado à montante do pivot de irrigação existente (usuário 1) no ponto de

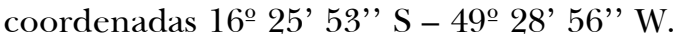
Neste ponto foram medidas as vazões em 13 de junho de 2003, 11 de setembro de 2003, 18 de dezembro de 2003 e 01 de abril de 2004.

- $\quad$ P2 - localizado imediatamente a jusante do pivot de irrigação existente (usuário 1) e à montante da captação da SANEAGO, utilizada para abastecimento urbano da cidade de Caturaí (usuário 2) no ponto de coordenadas $16^{\circ}$ 26' $04^{\prime \prime}$ S - 49 29' $05^{\prime}$ ' W. Neste ponto foram medidas as vazões em 13 de junho de 2003, 11 de setembro de 2003 e 01 de abril de 2004.

- $\quad$ P3 - localizado imediatamente a jusante da captação da SANEAGO (usuário 2) no ponto de coordenadas $16^{\circ} 26^{\prime} 29^{\prime \prime} \mathrm{S}-49^{\circ}$ 29' 09' W. Neste ponto foram medidas as vazões em 13 de junho de 2003, 11 de setembro de 2003, 18 de dezembro de 2003 e 01 de abril de 2004.

- P4 - localizado na Foz do Rio do Peixe, aproximadamente a 500 metros de sua desembocadura no Rio Anicuns, no ponto de coordenadas $16^{\circ} 30^{\prime} 04^{\prime}$ 'S e 4940' $51^{\prime}$ ' W. Neste ponto foram realizadas medições de vazões em 07 de novembro de 2003, 18 de dezembro de 2003 e 01 de abril de 2004.

As medições foram realizadas pelo método do molinete fluviométrico. 
RBRH - Revista Brasileira de Recursos Hídricos Volume 11 n.2 Abr/Jun 2006, 47-58

Tabela 4 - Usos de águas na sub-bacia do Rio do Peixe, Bacia do Rio dos Bois, Estado de Goiás, até novembro/2004.

\begin{tabular}{|c|c|c|c|c|}
\hline \multicolumn{5}{|l|}{ USOS CONSUNTIVOS } \\
\hline Tipo de uso & Outorgas requeridas & Outorgas expedidas & Vazão requerida & Vazão outorgada \\
\hline Irrigação & 3 & 3 & $66,55 \mathrm{l} / \mathrm{s}$ & $66,55 \mathrm{l} / \mathrm{s}$ \\
\hline Indústria & 1 & 1 & $75,18 \mathrm{l} / \mathrm{s}$ & $75,18 \mathrm{l} / \mathrm{s}$ \\
\hline Abastecimento Público & 1 & 0 & $20,00 \mathrm{l} / \mathrm{s}$ & \\
\hline Total & 5 & 4 & $161,83 \mathrm{l} / \mathrm{s}$ & $141,83 \mathrm{l} / \mathrm{s}$ \\
\hline \multicolumn{5}{|c|}{ USOS NÃO CONSUNTIVOS } \\
\hline Tipo de uso & \multicolumn{2}{|c|}{ Outorgas requeridas } & \multicolumn{2}{|c|}{ Outorgas expedidas } \\
\hline Barramento & \multicolumn{2}{|l|}{2} & \multicolumn{2}{|l|}{1} \\
\hline
\end{tabular}

Para a determinação da porção alocável na sub-bacia do Rio do Peixe considerou-se o critério atualmente adotado pela autoridade outorgante, que estabelece que cerca de $15 \%$ da menor vazão medida no manancial pode ser outorgada aos diferentes usos e usuários.

Os usos de águas existentes na sub-bacia do Rio do Peixe foram identificados por duas metodologias diferentes, a primeira pela consulta ao Sistema de Outorga da Superintendência de Recursos Hídricos da Secretaria do Meio Ambiente e dos Recursos Hídricos de Goiás (SEMARH-GO), incluindo os usos solicitados e indeferidos, classificados como usos potenciais. A segunda pelo levantamento in loco, no qual foram dimensionados e registrados os usos efetivos, outorgados ou não.

Pela inexistência de definição das vazões insignificantes, foram considerados apenas os usos capazes de repercutir na captação para abastecimento público do município de Caturaí, de acordo com os critérios da SEMARH-GOIÁS.

Os usos foram classificados em captação e consumo (Tabela 4).

\section{RESULTADOS E DISCUSSÃO}

A definição da capacidade de geração de recursos financeiros através da cobrança pelo uso de recursos hídricos em uma bacia hidrográfica está condicionada, entre outros fatores, à identificação do potencial de usos na bacia, que é função das atividades usuárias já instaladas e daquelas suportáveis pela disponibilidade hídrica conhecida. Estes estudos devem ser precedidos, portanto, do estabe- lecimento da vazão máxima alocável, que é normalmente parte da vazão de referência adotada.

Obregon (1999), ao estudar o emprego de séries de vazão estendidas para a regionalização, afirma que, em bacias com carência de dados hidrológicos, a regionalização de vazões constitui um procedimento muito valioso para a avaliação dos recursos hídricos.

Pode-se considerar que a área abrangida pela Bacia Hidrográfica do Rio dos Bois conta com boa disponibilidade de dados fluviométricos, fornecidos por 20 estações.

Ao testar a confiabilidade dos dados entre a Estação Ponte Sul Goiana e a Estação Maurilândia, foi obtido coeficiente de correlação de 0,9264 , considerado satisfatório para a utilização dos dados.

A distribuição dos pontos em torno da curva de correlação pode ser observada no Gráfico 1. A Estação Ponte Sul Goiana, por ter maior área de drenagem em relação ao total da bacia, forneceu os dados para os estudos de regionalização das vazões de permanência na saída da bacia.

Estudos recentes, realizados para a elaboração do Plano Diretor de Irrigação em Goiás (Gama, 2004), calcularam as curvas de permanência para os locais das estações fluviométricas próximos das saídas da bacia do Rio dos Bois e suas sub-bacias, onde se executou a transposição para as saídas das bacias, com base na área de drenagem.

A partir das séries históricas disponíveis para a primeira estação à montante da saída da bacia do Rio dos Bois (Estação Ponte Sul Goiana), foi calculada, empregando-se o programa RH 3.0, a disponibilidade hídrica na bacia, representada pelas vazões com garantia de permanência em $90 \%$ do tempo $\left(Q_{90}\right)$, em $95 \%$ do tempo $\left(Q_{95}\right)$ e em $99 \%$ do tempo $\left(Q_{99}\right)$. As vazões obtidas estão apresentadas na Tabela 5. 
Tabela 5 - Disponibilidade hídrica na Bacia Hidrográfica do Rio dos Bois, Estado de Goiás.

\begin{tabular}{|c|c|c|}
\hline $\mathbf{Q}_{\mathbf{9 0}}(\mathbf{l} / \mathbf{s})$ & $\mathbf{Q}_{\mathbf{9 5}}(\mathbf{l} / \mathbf{s})$ & $\mathbf{Q}_{\mathbf{9 9}}(\mathbf{l} / \mathbf{s})$ \\
\hline 150.400 & 118.100 & 55.900 \\
\hline
\end{tabular}

Fonte: GAMA, 2004

No Estado de Minas Gerais, o programa foi empregado na regionalização hidrológica para $96 \%$ do território. Foi também empregado na Bacia do Rio Amazonas, na sub-bacia do Rio Purus e vem sendo aplicado como apoio à elaboração de diferentes Planos Diretores de Recursos Hídricos e por instituições públicas e privadas, seja na gestão dos recursos hídricos ou na área de projetos e pesquisas. Em âmbito internacional, vem sendo utilizado pela empresa espanhola EPTISA (www.ufv.br/ dea/ hidrotec).

Euclydes et al (2001), empregaram o programa computacional RH 3.0 para regionalização hidrológica na bacia do alto São Francisco, obtendo as vazões com permanência de $50 \%$ a $95 \%$, após a identificação das regiões hidrologicamente homogêneas.

Segundo Hidrocon (2001) as vazões médias mensais de longo período calculadas para a Estação Ponte Sul Goiana, a mais próxima da saída da bacia, são de $182.000 \mathrm{l} / \mathrm{s}$ (menor vazão média mensal de longo período, correspondente ao mês de agosto) e $995.000 \mathrm{l} / \mathrm{s}$ (maior vazão média mensal de longo período, correspondente ao mês de março).

Segundo Arnéz (2002), para a formulação de um sistema de outorga, é necessária a definição da vazão outorgável, obtida a partir da vazão de referência, da qual um percentual é objeto de outorga, enquanto o restante constitui vazão ecológica, a ser mantida no leito do rio para proteção do ecossistema.

A escolha da vazão de referência para a determinação da vazão máxima alocável, principal subsídio à decisão da outorga de direito de usos de águas, deve ser feita a partir da compreensão dos efeitos da adoção de cada uma delas para os usos e usuários de água e também dos reflexos dessa escolha na oferta de recursos hídricos.

Schvartzman et al (2002), ao analisarem a aplicação do instrumento da outorga de direito de uso das águas em uma bacia hidrográfica em Minas Gerais, afirmaram que, em algumas bacias hidrográficas, o critério de outorgar-se apenas $30 \%$ da $Q_{7,10}$ (vazão mínima com sete dias de duração e período de retorno de dez anos), adotado no Estado de Minas Gerais, poderá tornar-se muito restritivo no atendimento das demandas das diversas classes de usuários e que, provavelmente, na maior parte do tempo, as vazões observadas nos rios serão superiores àquelas porcentagens.

Entre os Estados brasileiros que estabeleceram, através de decretos, portarias dos órgãos gestores ou resoluções de conselhos estaduais, critérios para a outorga de direito de uso das águas, tem-se dois grupos distintos no que diz respeito à vazão de referência adotada.

Nos Estados da região nordeste e no Distrito Federal, a vazão de referência adotada é a vazão de permanência em $90 \%$ do tempo, enquanto nos Estados das regiões sul e sudeste, adota-se a vazão mínima de duração de 7 dias, com período de retorno de 10 anos $\left(Q_{7,10}\right)$, conforme demonstrado na Tabela 6 .

Esta distinção é facilmente compreendida quando é feita a comparação entre a distribuição de chuvas nessas regiões. Onde as chuvas são uniformemente distribuídas ao longo do ano, a $Q_{7,10}$ corresponde a um valor não tão restritivo quanto nas regiões onde há um período de estiagem e outro de chuvas. Nas regiões onde a precipitação se concentra em um período do ano, como o caso do Estado de Goiás, a vazão crítica de estiagem $\left(Q_{7,10}\right.$ ou $\left.Q_{99}\right)$ não reflete a realidade do volume de água disponível na bacia durante o ano.

Em Goiás, por exemplo, onde as estações chuvosas e secas são bem distintas, os estudos realizados para a elaboração do Plano Diretor de Irrigação (Gama, 2004), concluíram que na maior parte das bacias hidrográficas, a $Q_{7,10}$ praticamente corresponde à $Q_{99}$, ou seja, trata-se de uma vazão correspondente a períodos críticos de estiagem.

Para a determinação da vazão alocável na Bacia Hidrográfica do Rio dos Bois, é necessário observar os critérios adotados pela autoridade outorgante no Estado de Goiás. A Resolução no 09, de 04 de maio de 2005, aprovada pelo Conselho Estadual de Recursos Hídricos de Goiás (CERH-GO) estabelecendo o regulamento do sistema de outorga de direito de uso das águas de domínio estadual, determina a adoção da $Q_{95}$ como vazão de referência. 
Tabela 6 - Principais critérios de outorga adotados nos Estados brasileiros

\begin{tabular}{|l|l|l|}
\hline Estado & Previsão Legal & Vazão Máxima Outorgável \\
\hline Distrito Federal & Decreto 22.359/2001 & $80 \% \mathrm{Q}_{90}$ \\
\hline Bahia & Decreto 6.296/97 & $\begin{array}{l}80 \% \mathrm{Q}_{90} \text { para todos } \\
20 \% \mathrm{Q}_{90} \text { por usuário }\end{array}$ \\
\hline Ceará & Decreto 23.067/94 & $90 \% \mathrm{Q}_{90}$ \\
\hline Alagoas & Decreto 006/2001 & $90 \% \mathrm{Q}_{90}$ \\
\hline Paraíba & Decreto 19.260/97 & $90 \% \mathrm{Q}_{90}$ \\
\hline Sergipe & Resolução 01/01 CONERH & $30 \% Q_{90}$ \\
\hline Rio Grande do Norte & Decreto 13.283/97 & $90 \% Q_{90}$ \\
\hline Paraná & Inexistente & $50 \% Q_{7,10}$ \\
\hline Rio de Janeiro & Portaria SERLA 307/2002 & $50 \% Q_{7,10}$ \\
\hline Minas Gerais & Portarias IGAM No 030/90, & $30 \% Q_{7,10}$ \\
\hline São Paulo & Dio/98 e 007/99 & Não definido \\
\hline
\end{tabular}

Tabela 7 - Resultado consolidado das vazões finais medidas nos pontos amostrados da sub-bacia do Rio do Peixe, Bacia Hidrográfica do Rio dos Bois, Estado de Goiás.

\begin{tabular}{|l|l|l|l|l|}
\hline DATA & P1 & P2 & P3 & P4 \\
\hline $13 / 06 / 2003$ & $124,67 \mathrm{l} / \mathrm{s}$ & $147,93 \mathrm{l} / \mathrm{s}$ & $155,96 \mathrm{l} / \mathrm{s}$ & - \\
\hline $11 / 09 / 2003$ & $70,50 \mathrm{l} / \mathrm{s}$ & $48,61 \mathrm{l} / \mathrm{s}$ & $60,08 \mathrm{l} / \mathrm{s}$ & - \\
\hline $07 / 11 / 2003$ & - & - & - & $679,751 / \mathrm{s}$ \\
\hline $18 / 12 / 2003$ & $95,40 \mathrm{l} / \mathrm{s}$ & - & $63,58 \mathrm{l} / \mathrm{s}$ & $626,651 / \mathrm{s}$ \\
\hline $01 / 04 / 2004$ & $138,66 \mathrm{l} / \mathrm{s}$ & $239,58 \mathrm{l} / \mathrm{s}$ & $207,57 \mathrm{l} / \mathrm{s}$ & $3.705,261 / \mathrm{s}$ \\
\hline
\end{tabular}

Segundo este critério, a vazão de referência adotada para a bacia do Rio dos Bois é de 118.100 $1 / \mathrm{s}$.

A vazão máxima outorgável adotada na maioria dos Estados brasileiros varia de $30 \%$ a $90 \%$ da vazão de referência. A resolução do CERH-GO n. ${ }^{\circ}$ 09/2005 estabelece como vazão máxima outorgável uma parte equivalente a $70 \%$ da vazão de referência. Com base no exposto, a vazão máxima alocável e, portanto, o potencial de uso de água na Bacia Hidrográfica do Rio dos Bois, é de 82.670 1/s, ou $70 \%$ da $Q_{95}$ calculada para a saída da bacia.

A realidade observada na sub-bacia do Rio do Peixe foi a inexistência total de dados, o que se repete para a maioria dos mananciais do Estado de Goiás, quando se trata de bacias hidrográficas de menor porte. Neste caso existe também a impossibilidade de transposição de dados da bacia do Rio dos Bois, pois a diferença entre a área de drenagem até a estação e a área de drenagem total da bacia supera o máximo recomendável para cálculos de regionalização de vazão (Tucci, 1997).
Esta situação está prevista na resolução aprovada pelo CERH-GO, que determina que, na ausência de informações hidrológicas que permitam o cálculo da $Q_{95}$, seja utilizada como vazão de referência a menor vazão medida no manancial, preferencialmente em período de estiagem e com método de precisão.

Segundo Silva Jr (2001), as variáveis hidrológicas de pequenas bacias, devido à escassez de dados nas mesmas, são obtidas através da transferência de informações hidrológicas de grandes bacias, que normalmente têm maior disponibilidade de dados hidrológicos.

No entanto, Silveira et al (1998), ao desenvolverem estudo para a quantificação de vazão em pequenas bacias hidrográficas, constataram que a atual rede hidrometeorológica brasileira contempla as grandes bacias hidrográficas, com áreas maiores que $500 \mathrm{~km}^{2}$, e que as pequenas bacias, com áreas de drenagem inferiores a $100 \mathrm{~km}^{2}$, apresentam carência quase total de dados. Afirmam também que a carência de dados fluviométricos leva a gran 
Gráfico 2 - Conflitos pelo uso da água na Bacia Hidrográfica do Rio dos Bois, de 1998 a 2004.

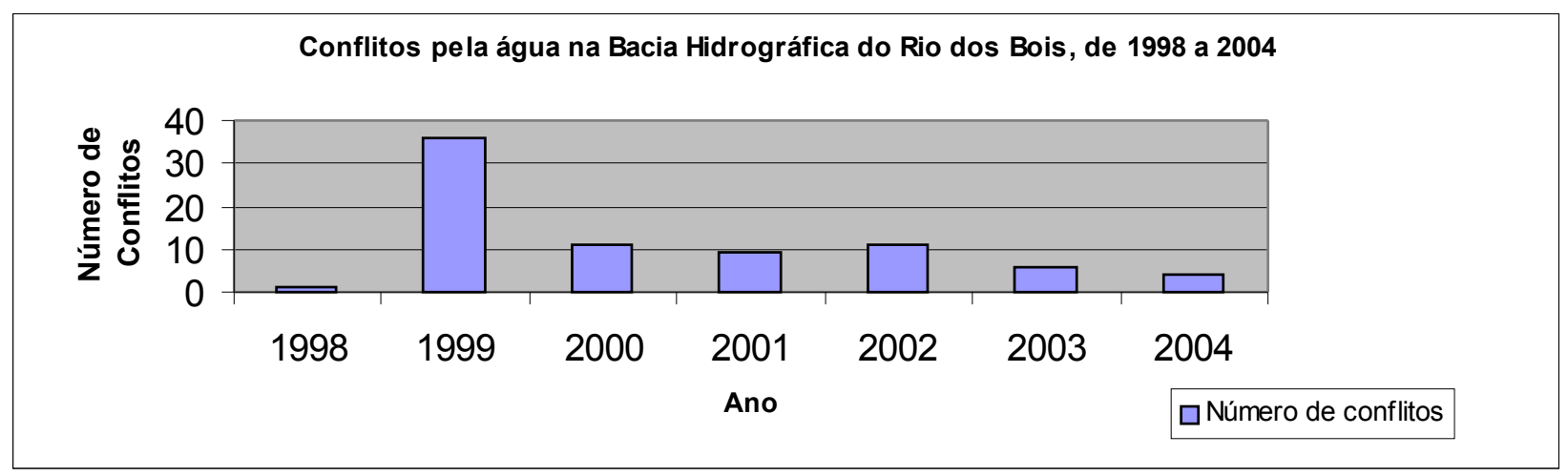

des incertezas na avaliação quantitativa dos recursos hídricos.

Devido à carência total de dados de estações fluviométricas na área da sub-bacia do Rio do Peixe, a determinação da vazão de referência foi feita por medições de vazão na saída da bacia. Os resultados obtidos nas medições de vazões do Rio do Peixe nos quatro pontos previamente demarcados estão contidos na Tabela 7.

Adotando-se o critério da autoridade outorgante estadual, que emprega como vazão de referência a menor vazão medida no manancial, obteve-se para a sub-bacia do Rio do Peixe, no ponto mais próximo à sua foz (Ponto 4), o valor de $627 \mathrm{l} / \mathrm{s}$.

Na sub-bacia do Rio do Peixe, onde a vazão de referência foi definida com base em medições pontuais, pouco representativas das vazões de longo termo, o critério atualmente adotado pela autoridade outorgante é mais restritivo, ficando em torno de $15 \%$ da menor vazão medida. Neste critério, obtevese a vazão alocável para a sub-bacia do Rio do Peixe em 94 l/s.

A partir da comparação entre os resultados obtidos das vazões alocáveis, ou seja potencial de alocação de água e os dos usos atualmente regularmente exercidos, ou seja a vazão já comprometida com usos instalados, é possível discutir a sustentabilidade da oferta hídrica na Bacia.

Na Bacia Hidrográfica do Rio dos Bois a vazão outorgada $(30.127,82 \mathrm{l} / \mathrm{s})$ corresponde a aproximadamente $36 \%$ da vazão alocável, o que sugere uma perspectiva de incremento de novos usos, sem comprometimento dos estoques hídricos e assegurando os usos prioritários. Apesar dos conflitos identificados na região, conforme se observa no Gráfico 2, não há registro de desabastecimento, exceto no ano de 1999, relacionado com um período de estiagem excepcional.

Na sub-bacia do Rio do Peixe, a vazão alocável, obtida com medições pontuais, foi superada pela vazão outorgada para usos consuntivos (94 l/s para a primeira e 141,83 l/s para a segunda). Ainda assim, o abastecimento urbano do município de Caturaí foi preservado.

Para ambas as bacias, a intensificação da política de incentivo à acumulação prévia em período chuvoso do volume a ser utilizado no período seco pode diminuir os riscos de desabastecimento dos usuários, sejam eles já instalados ou não.

Além disso, recomenda-se a instalação de uma rede de monitoramento de dados hidrometeorológicos, com estações em número e pontos suficientes para gerar as informações necessárias à determinação precisa e confiável das vazões máximas alocáveis para toda a bacia e suas sub-bacias.

\section{REFERÊNCIAS}

ARNÉZ, F.A. Análise de critérios de outorga de usos da água na bacia do rio Santa Maria, RS, dissertação de mestrado, IPH-UFRGS, 2002.

BOULDING. K. E. The Economics of the Coming Spaceship Earth. In: DALY, H.E.; TOWNSEND, K.N. Valuing the Earth. Economics, Ecology, Ethics. Massachussetts: The MIT Press Cambridge, 1993.

BRASIL. Ministério do meio Ambiente. Secretaria de Recursos Hídricos. Recursos Hídricos: conjunto de normas legais. Brasília: Ministério do Meio Ambiente, 2004. 
CONSTANZA, R. Frontiers in Ecological Economics. Cheltenham, UK: Edward Elgar Publishing Limited, 1997.

CORTÊS, F.C.. Obtenção e validação de modelos de regionalização de vazão na Bacia do Rio dos Bois, Estado de Goiás, dissertação de mestrado de Ciências Agrárias, UNB, 2004.

DINAR, A., SUBRAMANIAN, A. Water Pricing Experiences - An International Perspective, World Bank Technical Paper $n^{0}$ 386, $164 \mathrm{p}$.

EUCLYDES, H. P., FERREIRA, P. A., RUBERT, O. A. V., SANTOS, R. M. Regionalização hidrológica na bacia do alto São Francisco a montante da barragem de Três Marias, Minas Gerais. In: Revista Brasileira de Recursos Hídricos. Porto Alegre: ABRH, 2001. Vol.6, n.2. P.81 a 105.

GAMA Engenharia e Consultoria Ltda. Assessoria Técnica Referente à Implantação e Operação de Projetos de Irrigação no Estado de Goiás e Elaboração do Plano Diretor de Irrigação - Relatório de andamento referente ao mês de março de 2004. Não Publicado. Goiânia: Secretaria de Planejamento e Desenvolvimento, SEPLAN, 2004.

HIDROCON Consultoria e Engenharia Ltda. Estudo Hidrológico do Rio dos Bois - Edealina/Pontalina GO. Goiânia, 2001. Não Publicado.

MOTA, J.A. O Valor da Natureza - economia e política de recursos naturais. Rio de Janeiro: Garamond, 2001.

OBREGON, E., TUCCI, C. E. M., GOLDENFUM, J. A. Regionalização de vazões com base em séries estendidas: bacias afluentes à Lagoa Mirim, RS. In: Revista Brasileira de Recursos Hídricos. Porto Alegre: ABRH, 1999. Vol. 4, N. 1, P. 57 a 75.

PERMAN, R., MA, Y., McGILVRAY, J., COMMON, M. Natural Resource and Environmental Economics. Essex, Inglaterra: Longman, 1999.

SCHVARTZMAN, A. S., NASCIMENTO, N. O., SPERLING, M. Outorga e cobrança pelo uso dos recursos hídricos: aplicação à bacia do Rio Paraopeba, MG. In: Revista Brasileira de Recursos Hidricos. Porto Alegre: ABRH, 2002. Vol.7, n.1. P.103 a 122.

SILVA JR., O. B. Análise da escala das variáveis hidrológicas e do uso do solo na bacia do Potiribu - RS, dissertação de mestrado, IPH-UFRGS, 2001.

SILVEIRA, G. L., TUCCI, C. E. M., SILVEIRA, A. L. L. Quantificação de vazão em pequenas bacias sem dados. In: Revista Brasileira de Recursos
Hídricos. Porto Alegre: ABRH, 1998. Vol. 3, N. 3, P. 111 a 131.

TUCCI, C. E. M. Hidrologia - Ciência e Aplicação. Porto Alegre: Editora da Universidade, UFRGS, 1997.

TUNDISI, J. G., TUNDISI, T. M., ROCHA, O. Limnologia de Águas Interiores. Impactos, Conservação e Recuperação de Ecossistemas Aquáticos. In: Águas Doces no Brasil: capital ecológico, uso e conservação. Rebouças, A. C., Braga, B., Tundisi, J. G. (organizadores). São Paulo: Escrituras Editora, 2002. P. 153 a 194.

www.ufv.br/dea/hidrotec, acessado em 15 de outubro de 2004.

\section{Evaluation of Allocatable Flows in the Bois River Basin and Peixe River Sub-basin in the State of Goiás}

\section{ABSTRACT}

This study evaluates the flows that can be allocated to users in the Bois River Basin and its sub-basin, Peixe River Basin, in Goiás, in order to provide information for water resources management instruments established by Federal Law 9.433/97, emphasizing charging for the use of water resources.

The Bois River Basin covers 34,552.04 km², corresponding to $10 \%$ of the total area of Goiás. A large amount of river flow data is available, supplied by twenty stations, with historical series and distribution that allowed the regionalization of the flows at the exit from the basin. The RH 3.0 software was developed by Minas Gerais Rural Foundation - RURALMINAS and Federal University of Viçosa, with the support of the Department of Water Resources of the Ministry of the Environment. It was used to estimate the guaranteed flow $95 \%$ of the time $\left(Q_{95}\right)$ to the outflow from Bois River Basin, obtaining the value of $118.100 \mathrm{l} / \mathrm{s}$.

The Goias State Council for Water Resources (CERH$G O)$, in resolution 09/2005, established $Q_{95}$ as reference flow for water use rights under the state domain. The maximum flow that can be allocated corresponds to $70 \%$ of $Q_{95}$, or, for the Bois River Basin, $82.670 \mathrm{l} / \mathrm{s}$.

To check the feasibility of using this reference flow and the portion allocated, the study performed a survey of the criteria used in eleven Brazilian states.

The Peixe River Basin has a drainage area of 287.49 $\mathrm{km}^{2}$. In this basin, the complete lack of hydrological data and the impossibility of data transfer because of the small drainage area prevent the calculation of $Q_{95}$ and its use as 
reference flow. Such situations are common in most small river basins in Goiás.

In such cases, according to CERH-GO resolution 09/2005, the smallest flow ever measured, preferably during a drought period using a precision method, is used as reference.

To obtain the reference flow in the Peixe River Basin, flow measurements were performed using a current meter, at four points in the basin, along the main course, on four occasions, from June, 2003 to April, 2004.

The reference flow at the end of Peixe River Basin was obtained from these measures, with the value of $627 \mathrm{l} / \mathrm{s}$, which corresponds to the smallest flow measured at that place. The part of the flow that can be allocated from the reference flow was obtained based on the criteria adopted by the water management authority, with a value of $94 \mathrm{l} / \mathrm{s}$.

Key-words: Flows allocated; river basin. 